\title{
An Experimental and Numerical Approach for the Welding Effects on the Duplex Stainless Steel Microstructure
}

\author{
Carlos Roberto Xavier ${ }^{a, b *}$, Horácio Guimarães Delgado Junior ${ }^{c, d}$, José Adilson de Castro ${ }^{e}$ \\ ${ }^{a}$ Departamento de Engenharia Mecânica, Centro Universitário de Volta Redonda-UniFOA, \\ Av. Paulo E. A. Abrantes, 1325, Três Poços, CEP 27240-560, Volta Redonda, RJ, Brasil \\ ${ }^{b}$ PETROBRAS, Rio de Janeiro, RJ, Brasil \\ ${ }^{c}$ Departamento de Mecânica e Energia, Faculdade de Tecnologia, Universidade do Estado do \\ Rio de Janeiro - UERJ, Rod. Pres. Dutra, Km 298, CEP 27537-000, Resende, RJ, Brasil \\ ${ }^{d}$ Departamento de Engenharia Civil, Centro Universitário de Volta Redonda-UniFOA, \\ Av. Paulo E. A. Abrantes, 1325, Três Poços, CEP 27240-560, Volta Redonda, RJ, Brasil \\ ePrograma de Pós-Graduação em Engenharia Metalúrgica e Mecânica, Universidade Federal \\ Fluminense-UFF, Av. dos Trabalhadores, 420, Vila Santa Cecília, CEP 27255-125, Volta Redonda, RJ, \\ Brasil
}

Received: June 11, 2014; Revised: May 17, 2015

Key microstructural changes that occur when Duplex Stainless Steels (DSS) are welded could be evaluated when bead-on-plate welding was carried out on a 2205 DSS by the GMAW process. By using numerical simulations, it was possible to calculate locally the heating and cooling rates taking place during the 2205 DSS welding and discuss its correlation to the microstructural changes experimented by the parent metal. Results showed that increasing heat input has promoted the ferritic grain growth with a slight reduction in the austenite content present at the high temperature heat affected zone (HTHAZ), whereas the cooling rates remained above from those reported as critical for sigma phase precipitation in 2205 DSS. Furthermore, nitrogen has proved to be an effective austenite former at the fusion zone (FZ), which can contributes to get a balanced microstructure in DSS welds in contrast to the effects from the elevated cooling rates.

Keywords: duplex stainless steel, welding, numerical simulation, microstructure, heat input, shielding gas

\section{Introduction}

Duplex stainless steels (DSS) have a ferritic-austenitic microstructure which confers them an excellent combination of properties such as toughness, strength and corrosion resistance allied to a competitive cost. Due to these characteristics, the DSS are very attractive materials for application in engineering designs where higher performance is required, thus justifying their increasing application, among others, by the chemical, petrochemical, petroleum and power generation industries. It is claimed that excellent combinations of properties for DSS are obtained when ferrite/austenite ratio is close to $50: 50^{1}$, but it is also accepted that any of the two phases, which is lower in percentage, must not be less than $30 \%{ }^{2}$. However, DSS are frequently submitted to welding operations and, depending on the thermal history undergone by the material during this procedure, the precipitation of brittle intermetallic phases such as sigma $(\sigma)$ and $\operatorname{chi}(\chi)^{3-9}$ may occur besides of impairing the adequate balance between the fractions of the ferrite and austenite phases at the heat affected zone (HAZ). In terms of secondary phases, the sigma phase is the most important intermetallic compound that could precipitate, since it has a deleterious influence on the mechanical properties and corrosion resistance of the DSS and higher

*e-mail: carlos.xavier@foa.org.br volumetric fraction observed among all them ${ }^{10-16}$. In fact, some works ${ }^{11-13,17-21}$ have shown that the impact toughness and corrosion resistance of the DSS drastically decrease even in the presence of very low amounts of sigma phase. Sigma phase is a hard, brittle and non-magnetic intermetallic phase with a tetragonal crystalline structure being formed basically by elements $\mathrm{Fe}, \mathrm{Cr}$ and $\mathrm{Mo}^{3,10,14}$ and usually forms after long holding times at temperatures between 650 and $950{ }^{\circ} \mathrm{C}$ and after cooling from high temperatures, as those occurring at the DSS HAZ during welding ${ }^{22}$.

Higher heat input implies lower cooling rate favoring austenite reformation at the HAZ, yields a more satisfactory balance between the fractions of ferrite and austenite, but makes also possible the precipitation of brittle intermetallic phases such as sigma phase and grain growth depending on the holding time and temperature reached by the weldment. On the other hand, lower heat input implies higher cooling rate, impairing the austenite reformation at the HAZ and favoring the ferrite phase. In both cases the impact toughness and corrosion resistance of the DSS will be seriously affected. Thus, the welding parameters should be controlled to ensure that the overall cooling conditions allow to attain an adequate austenite reformation avoiding, 
at the same time, deleterious precipitation at the HAZ. For this purpose, some guidelines have suggested heat input ranges for DSS welding. However, the optimum thermal cycles also depend on other kinds of variables, such as joint category and material thickness. In practice, cooling times between 800 and $500{ }^{\circ} \mathrm{C}\left(\Delta t_{8 / 5}\right)$, lying in the range of 8-30 $\mathrm{s}$, have been recommended ${ }^{23}$, corresponding approximately to $4-15 \mathrm{~s}$ for the cooling time between 1200 and $800{ }^{\circ} \mathrm{C}$ $\left(\Delta t_{12 / 8}\right)$, which is more relevant for DSS since in this interval is where the austenite reformation occurs.

Furthermore, some phases including secondary austenite $\left(\gamma_{2}\right)$, chromium nitrides and carbides also are prone to form during DSS welding, which can affect their properties as corrosion resistance and mechanical properties ${ }^{3,5,7,24-32}$. Secondary austenite can form in DSS as a result of reheating cycles, such as in multipass welding or post-weld heat treatment having as a critical result the loss of corrosion resistance of the weldment. According to thermal history of the welding, the secondary austenite in DSS can form during cooling as result of the $\alpha+\gamma \rightarrow \alpha+\gamma+\gamma_{2}$ transformations in the austenitic-ferritic structure. It may also directly to nucleate and to grow from the ferrite by the diffusional transformation $\left(\alpha \rightarrow \gamma_{2}\right)$ or may form as a result of the eutectoid decomposition of the ferrite $\left(\alpha \rightarrow \sigma+\gamma_{2}\right)^{7,24-26}$. Lower heat input implies in greater cooling rates, favoring the chromium nitrides formation in DSS welds and increases its susceptibility to pitting corrosion ${ }^{5,28-30}$. More ferrite will be present in DSS welds with increasing cooling rates due to the minor time available for that the diffusional transformation ferrite-austenite may occur. Taking it into account and the fact that ferrite possesses lower nitrogen solubility than austenite and the existence of a preferential morphological orientation relationship with the chromium nitride precipitates, it may be attributed to the ferrite a major role on the process of chromium nitrides precipitation in $\mathrm{DSS}^{1,5}$. Thus, in order to prevent the chromium nitrides precipitation in DSS welds, it is recommended the use of greater heat input during DSS welding, since slower cooling rates favors the austenite reformation by retarding the time for ferrite-austenite transformation, besides of promoting the diffusion of austenite-stabilizer elements such as nickel and nitrogen ${ }^{5,28-30}$. In despite of a minor role playing by carbides in moderns DSS due to the their very low carbon content ${ }^{12,32}$, typical carbides as $\mathrm{M}_{23} \mathrm{C}_{6}$ may occur in DSS welds and base metal, causing the same deleterious effects as those from the sigma phase ${ }^{31}$. The precipitation of $\mathrm{Cr}_{23} \mathrm{C}_{6}$ chromium carbides occur firstly at the ferrite/austenite interfaces and grows into the ferrite grains ${ }^{31}$, although some works have reported little or no occurrence of carbides in welds or after aging treatments of the $\operatorname{DSS}^{12,30}$. This latter can be also attributed to high solubility of carbon and nitrogen in the low nickel austenite phase and to a possible retarding effect of nitrogen on the carbide precipitation ${ }^{3}$.

In this work were investigated the effects of some welding variables such as heat input and shielding gas composition on some essential metallurgical transformations that occur when DSS are welded. For this purpose were used the 2205 DSS, the GMAW process and a numerical code was proposed to simulate this procedure. The possibility to predict and locally quantify the heat input effects on the thermal behavior enables a more accurate analysis from the microstructural changes that occur when DSS are welded and, accordingly, in the obtaining of more reliable data and information for designs involving their applications.

\section{Experimental Procedure}

The as-received base material was a hot rolled 2205 DSS produced by Aperam South America and whose chemical composition is shown in Table 1. Still during manufacturing process, the material was submitted to a solution treatment at $1100^{\circ} \mathrm{C}$ with subsequent water quenching in order to avoid the presence of intermetallic compounds, such as sigma phase and to ensure an approximately equal proportion between ferrite and austenite.

Bead-on-plate welding without applying preheating was carried out on $60 \times 220 \times 9.5 \mathrm{~mm}$ plates of 2205 DSS by the automated GMAW process. Thermal cycles were measured during welding by inserting thermocouples in the 2205 DSS plates and recorded it by a PC based high speed data acquisition unit. The welding parameters current, voltage and speed are in Table 2. In this study were used two kinds of shielding gas commercially produced by White Martins (Praxair, Inc.) (Table 3). A flow of 15 1/min was utilized for both shielding gasses A and B in all carried out experiments.

Six 2205 DSS samples were subjected to three different heat inputs during welding, being that three of these samples were welded using the shielding gas $\mathrm{A}$ and the remaining the shielding gas $\mathrm{B}$.

\subsection{Microstructural characterization}

Samples were analyzed by the light optical microscopy (LOM) after it has been grinded, polished and etched with the BERAHA II solution, which was composed by water $\left(\mathrm{H}_{2} \mathrm{O}\right)$, hydrochloric acid $(\mathrm{HCl})$ and potassium metabisulphite $\left(\mathrm{K}_{2} \mathrm{~S}_{2} \mathrm{O}_{5}\right)$, whereas the phases volumetric fraction was determined in 5 regions of interest by using an images analysis software.

Table 1. Base metal composition (wt. \%).

\begin{tabular}{cccccccccc}
\hline $\mathbf{C}$ & $\mathbf{M n}$ & $\mathbf{S i}$ & $\mathbf{P}$ & $\mathbf{S}$ & $\mathbf{C r}$ & $\mathbf{N i}$ & $\mathbf{M o}$ & $\mathbf{C u}$ & $\mathbf{N}$ \\
\hline 0.023 & 1.85 & 0.32 & 0.03 & 0.001 & 22.5 & 5.30 & 2.9 & 0.03 & 0.166 \\
\hline
\end{tabular}

Table 2. Welding parameters.

\begin{tabular}{ccccc}
\hline Arc voltage (volt) & Welding current (amp) & Welding speed $\left(\mathbf{m m ~ s}^{-\mathbf{1}}\right)$ & Thermal efficiency $(\boldsymbol{\eta})$ & Heat input $\left(\mathbf{k J} \mathbf{~ m m}^{-1}\right)$ \\
\hline 25 & 180 & 6.0 & 0.8 & 0.6 \\
30 & 200 & 3.0 & 0.8 & 1.6 \\
34 & 240 & 2.6 & 0.8 & 2.6 \\
\hline
\end{tabular}




\section{Numerical Model}

\subsection{Model setup}

The numerical model for simulation was built taking into account the needs of predicting the temperature field coupled dynamically with the welding process evolution and the material thermophysical properties. In this model the thermophysical properties were assumed as composition and temperature dependent for the material used in this study. Although the local properties of the phases are dynamically taken into account as averaged values of the ferrite and austenite proportions, the temperature effects of the locally averaged is dominant, which is justified by the accurate predictions of the temperature fields. On the other hand, the density of the steel was assumed constant throughout the domain due to easy calculations procedure and lack of accurate data varying with temperature and composition of the density for the materials under investigation. The process is modeled coupling the phenomena of heat transfer by radiation, convection and conduction with mass transfer, melting and solidification. Equation 1 represents the energy equation for a general coordinate system in compact form; $\rho$ is the density; $\mathrm{C}_{\mathrm{p}}$ is the specific heat, $\mathrm{k}$ is thermal conductivity and $\vec{U}$ is velocity field, which accounts for buoyancy driven flow in the liquid pool or moving mesh to match the geometry changes due to the metal deposition. $\mathrm{T}$ is the temperature field and $\mathrm{S}$ is

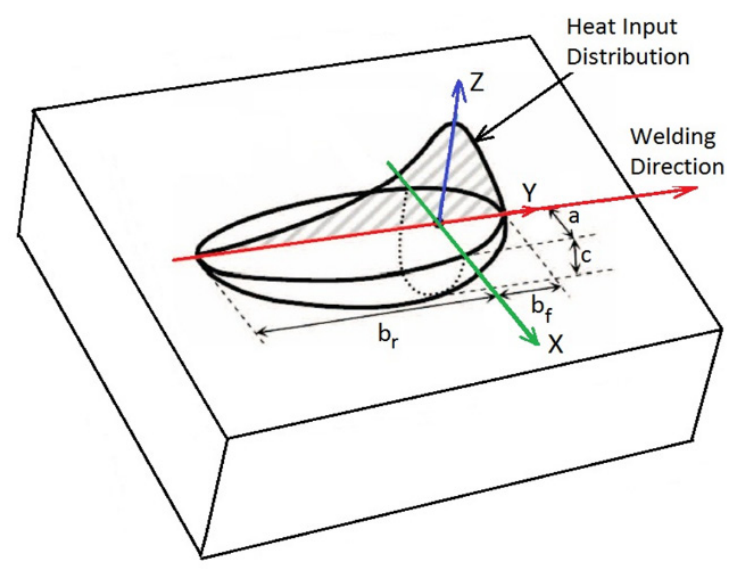

Figure 1. Schematic model for double-ellipsoid heat source ${ }^{33}$.

Table 3. Shielding gas composition.

\begin{tabular}{cc}
\hline Shielding Gas & Composition \\
\hline $\mathrm{A}^{*}$ & $95 \% \mathrm{Ar}-3 \% \mathrm{CO}_{2}-2 \% \mathrm{~N}_{2}$ \\
$\mathrm{~B}$ & $98 \% \mathrm{Ar}-2 \% \mathrm{O}_{2}$ \\
\hline
\end{tabular}

*Chemical composition and application patented by White Martins Company (Praxair, Inc.). the source term, which accounts for all source or sink due to phase transformations, melting and solidification. Details of the numerical implementation to solve Equation 1 are presented in Appendix A.

$$
\frac{\partial}{\partial t}\left(\rho C_{p} T\right)+\operatorname{div}\left[\rho C_{p}(\vec{U}) T\right]=\operatorname{div}[k(\operatorname{grad}(T))]+S
$$

\subsection{Initial and boundary thermal conditions}

Initial condition is assumed with the workpiece setup and an initial numerical mesh and a given temperature and composition constant for every mesh control volume. Thus the thermophysical properties are calculated given the initial settings of the model variables. The geometry is actualized for each time step after metal deposition according to the assumed welding speed. For the boundary conditions, the effects of convective and radioactive fluxes are considered, while the heat input supplied by the welding torch is modeled by the power distribution given by the moving Goldak's double-ellipsoid heat source model (Figure 1) ${ }^{33}$.

The model is a combination of two ellipses: one in the front quadrant of the heat source and the other in the rear quadrant. Equations 2 and 3 set up the heat flux distributions inside the front and rear quadrant of the heat source respectively. The model is defined as a function of position and time together with a number of parameters that affect the heat flux magnitude and distribution.

$$
\begin{aligned}
& \left.q_{r}(x, y, z)=\frac{6 \sqrt{3} f_{r} Q}{a b_{r} c \pi \sqrt{\pi}} e^{-3\left(\frac{x}{a}\right)^{2}} e^{-3\left(\frac{y}{b_{r}}\right)}\right)_{2} e^{-3\left(\frac{z}{c}\right)^{2}} \\
& q_{f}(x, y, z)=\frac{6 \sqrt{3} f_{f} Q}{a b_{f} c \pi \sqrt{\pi}} e^{-3\left(\frac{x}{a}\right)^{2}} e^{-3\left(\frac{y}{b_{f}}\right)} e^{-3\left(\frac{z}{c}\right)^{2}}
\end{aligned}
$$

The heat input rate $Q=\eta V I$ is defined by welding operational parameters current (I), voltage (V) and thermal efficiency $(\eta)$ respectively. The factors $f_{f}$ and $f_{r}$ denote the fraction of the heat deposited in the front and rear quadrant respectively, which are setup to attain $f_{f}+f_{r}=2$. The $a, b_{f}, b_{r}$ and $c$ are source constant parameters that define the size and shape of the ellipses, therefore the heat source distribution. The $a$ and $c$ parameters values of the doubleellipsoide model, corresponding to the width and depth of the molten zone respectively, were obtained directly of the cross-section from the experiment, while the parameters $b_{f}$ and $b_{r}$ were adjusted in order to get a good matching with the experimental results (Table 4). Finally, the factors $f_{f}$ and $f_{r}$ were defined to be 0.6 and 1.4 respectively.

Table 4. Welding and double-ellipsoid model parameters.

\begin{tabular}{cccccc}
\hline $\begin{array}{c}\text { Arc voltage } \\
(\mathbf{v o l t})\end{array}$ & $\begin{array}{c}\text { Welding current } \\
(\mathbf{a m p})\end{array}$ & $\begin{array}{c}\text { Welding speed } \\
\left(\mathbf{m m ~ s}^{-\mathbf{1}}\right)\end{array}$ & $\begin{array}{c}\text { Thermal } \\
\text { efficiency }(\boldsymbol{\eta})\end{array}$ & $\begin{array}{c}\text { Heat input } \\
\left(\mathbf{k J ~ m m}^{-1}\right)\end{array}$ & $\begin{array}{c}\text { Double-ellipsoid model } \\
\text { parameters }(\mathbf{m m})\end{array}$ \\
\hline 25 & 180 & 6.0 & 0.8 & 0.6 & $\mathrm{a}=3.4 ; \mathrm{b}_{\mathrm{f}}=4.5 ; \mathrm{c}=2.4 ; \mathrm{b}_{\mathrm{r}}=15.0$ \\
30 & 200 & 3.0 & 0.8 & 1.6 & $\mathrm{a}=5.1 ; \mathrm{b}_{\mathrm{f}}=6.4 ; \mathrm{c}=4.2 ; \mathrm{b}_{\mathrm{r}}=25.0$ \\
34 & 240 & 2.6 & 0.8 & 2.6 & $\mathrm{a}=7.9 ; \mathrm{b}_{\mathrm{f}}=9.8 ; \mathrm{c}=5.8 ; \mathrm{b}_{\mathrm{r}}=40.0$ \\
\hline
\end{tabular}


The cooling boundary conditions between the workpiece and environment by means of convection and radiation are calculated by the Equations 4 and 5 respectively.

$$
q_{c}=h\left(T-T_{0}\right)
$$

$$
q_{r}=\varepsilon \sigma\left(T^{4}-T_{0}^{4}\right)
$$

where $T_{0}\left(25^{\circ} \mathrm{C}\right)$ is the room temperature, $\varepsilon(0.6)$ is the emissivity, $\sigma\left(5.67 \times 10^{-8} W \cdot m^{-2} \cdot K^{-4}\right)$ is the Stefan-Boltzmann constant and $h\left(15 W . m^{-2} \cdot K^{-1}\right)$ is the natural convective heat coefficient assumed.

\subsection{Thermophysical properties}

The material properties were considered as temperature dependent. The averaged heat capacity and thermal conductivity are presented in Figures 2 and 3 respectively. Due to small variation of the density of 2205 DSS until melting, this property was established as constant value of $7800 \mathrm{~kg} \cdot \mathrm{m}^{-3}$.

\section{Results and Discussion}

\subsection{Thermal features}

Figure 4 shows a comparison between the experimental and calculated curves depicting the thermal cycles in a location from the HAZ where the peak temperature has reached about $1250{ }^{\circ} \mathrm{C}$, while that Figure 5 shows the $3 \mathrm{D}$

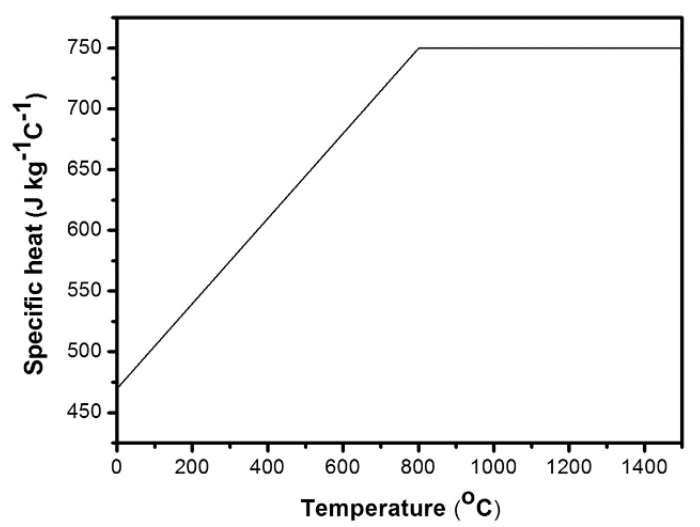

Figure 2. Temperature-dependent specific heat for base and weld metal.

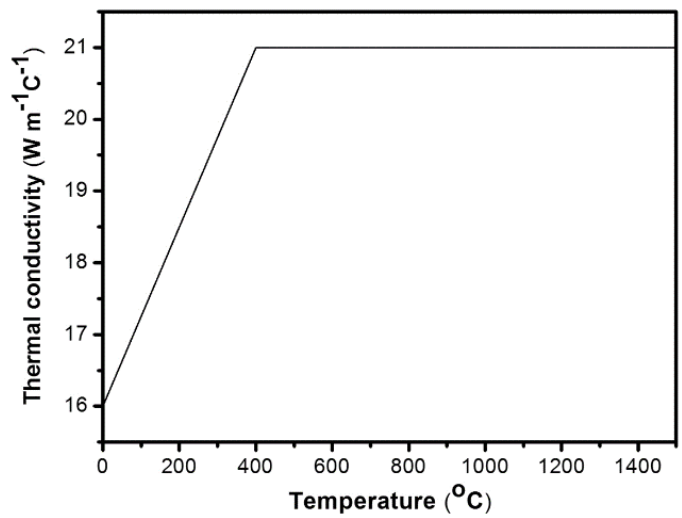

Figure 3. Temperature-dependent thermal conductivity for base and weld metal. results for temperature distribution from the 2205 DSS welding simulation using heat input of $0.6,1.6$ and $2.6 \mathrm{~kJ}$ $\mathrm{mm}^{-1}$. It can be seen in Figure 5 that isothermals became narrower when lowest heat input are used, which leads to larger temperature gradients directly affecting the cooling rates and, accordingly, the weld final microstructure.

\subsection{Microstructural features}

Figure 6 exemplifies the regions from the 2205 DSS that has been analyzed after welding, i.e., the fusion zone (FZ), the heat affected zone (HAZ) and the base metal (BM).

\subsubsection{Base metal}

Base metal (BM) had a fraction of $55 \%$ and $45 \%$ of austenite and ferrite respectively. The BERAHA-II etching solution made ferrite darker than austenite (Figure 7). The thickness of the elongated austenitic grains was approximately $8 \mu \mathrm{m}$ and no evidence of the sigma phase presence or others precipitates was noticed at the BM microstructure.

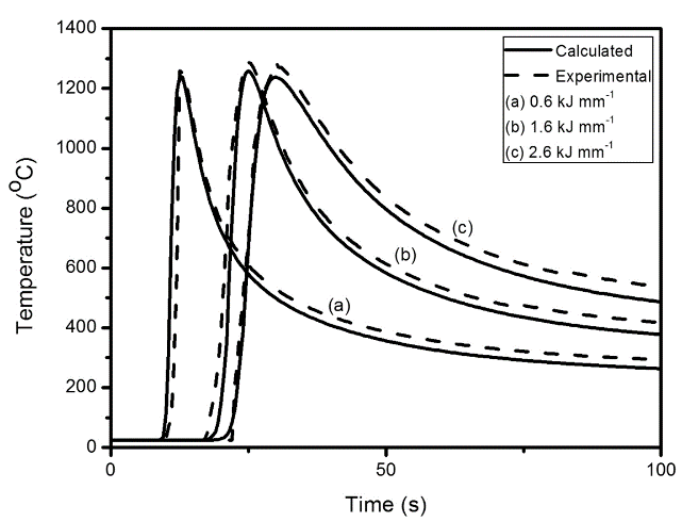

Figure 4. Comparison between calculated and measured thermal cycles.

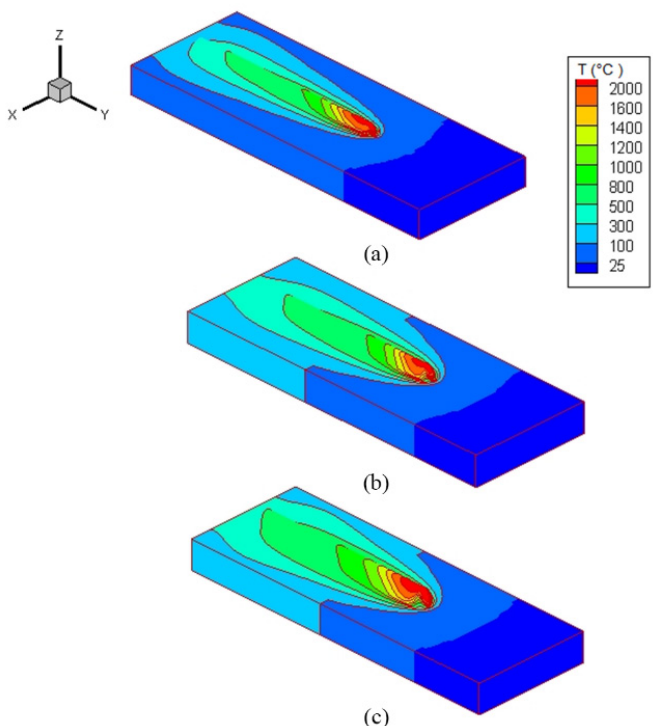

Figure 5. 3D numerical simulation: a) $0.6 \mathrm{~kJ} \mathrm{~mm}^{-1}$ b) $1.6 \mathrm{~kJ} \mathrm{~mm}^{-1}$ and c) $2.6 \mathrm{~kJ} \mathrm{~mm}^{-1}$. 


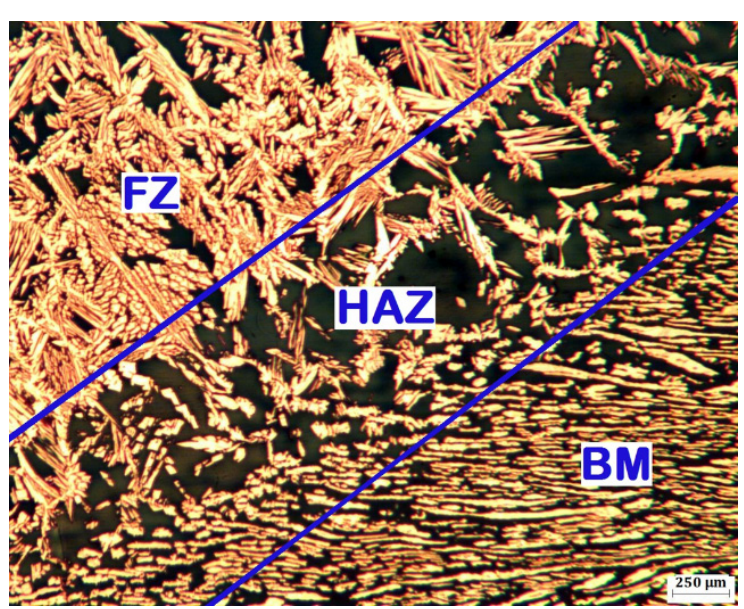

Figure 6. Optical micrograph from the evaluated regions after 2205 DSS welding.

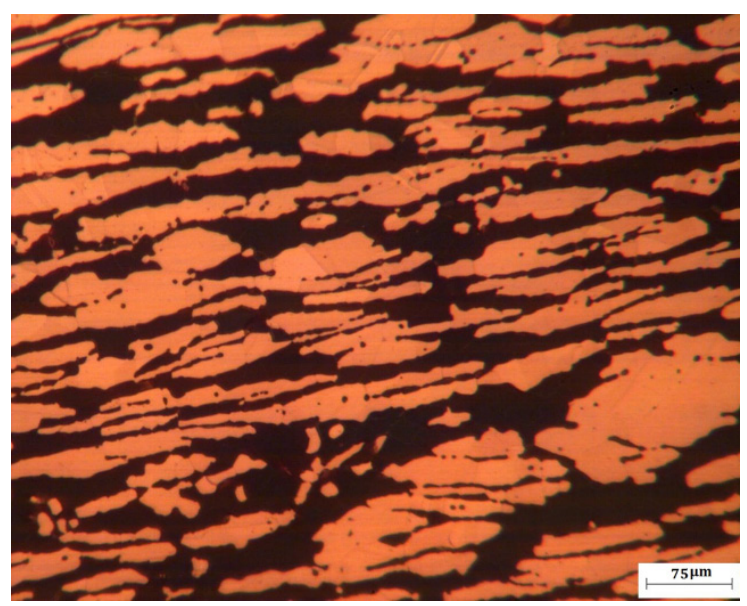

Figure 7. Optical micrograph from the BM: austenite and ferrite (dark phase).

\subsubsection{Heat affected zone}

In this section the discussion is carried out only based on the results obtained from the use of shielding gas A (see Table 3). The HAZ is subdivided in two sub-regions known as high temperature HAZ (HTHAZ) and low temperature HAZ (LTHAZ). The HTHAZ corresponds to the HAZ region near the fusion boundary where DSS is almost entirely ferritic on heating during welding. On the other hand, the LTHAZ is located away from the fusion boundary, where the balance between the phases fraction remains substantially unchanged. There is an special interest on the developed microstructure at the HTHAZ, since it can seriously impair the properties of the DSS as the toughness and the corrosion resistance when compared with the microstructure of the parent metal $1^{5,8,34}$. The pre-existing austenite was practically dissolved with the rapid thermal cycles and temperature peaks reached by the HTHAZ. Indeed, results from the numerical simulation showed that 2205 DSS was submitted to very high local heating and cooling rates during welding (Figures 8 to 10). The kind, amount, size and morphologies of the new formed phases will also be dependent on the intensity of these rates, which

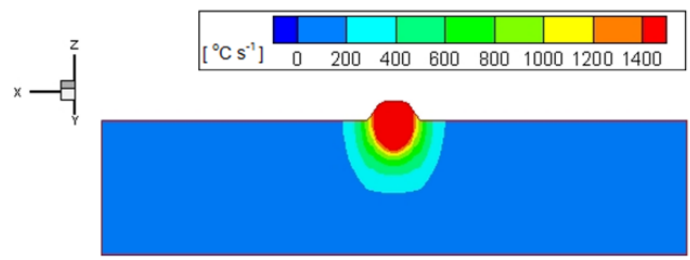

(a)

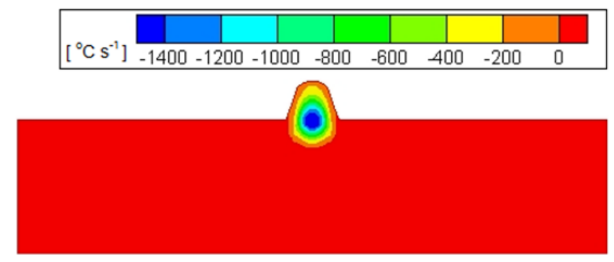

(b)

Figure 8. a) Local heating and b) cooling rates $\left({ }^{\circ} \mathrm{C} \mathrm{s}^{-1}\right)$ achieved in a same section of the plate during welding $\left(0.6 \mathrm{~kJ} \mathrm{~mm}^{-1}\right)$.

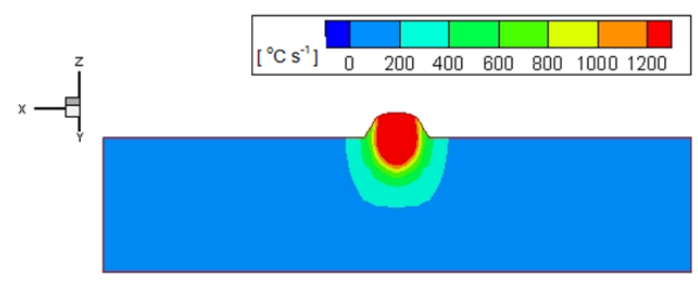

(a)

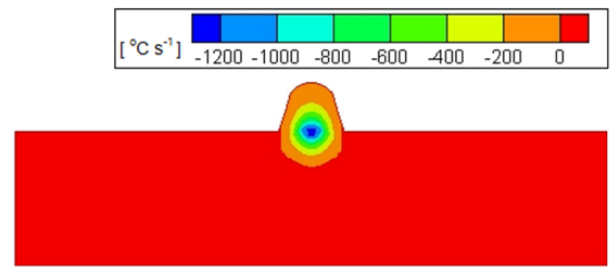

(b)

Figure 9. a) Local heating and b) cooling rates $\left({ }^{\circ} \mathrm{C} \mathrm{s}^{-1}\right)$ achieved in a same section of the plate during welding $\left(1.6 \mathrm{~kJ} \mathrm{~mm}^{-1}\right)$.

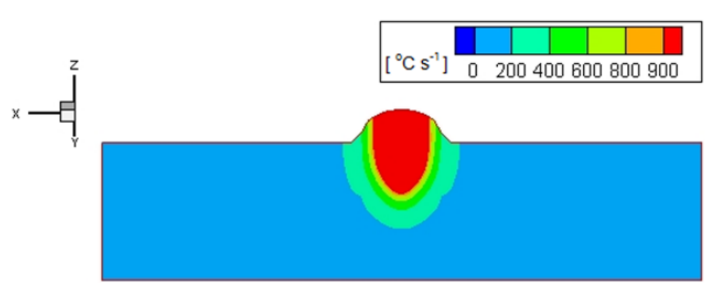

(a)

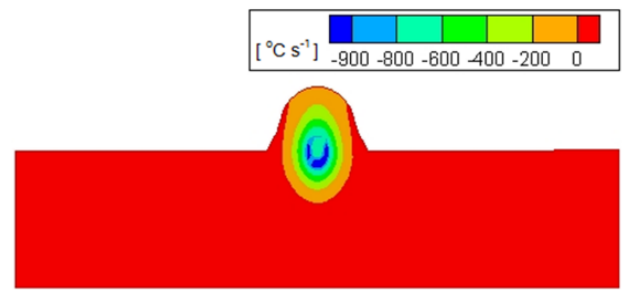

(b)

Figure 10. a) Local heating and b) cooling rates $\left({ }^{\circ} \mathrm{C} \mathrm{s}^{-1}\right)$ achieved in a same section of the plate during welding $\left(2.6 \mathrm{~kJ} \mathrm{~mm}^{-1}\right)$. 
has decreased their absolute values when higher heat input has been employed. New grain boundary austenite began to form during cooling at the interfaces between ferrite grains. Generally speaking, the microstructure became coarser with increasingly heat input, i.e., lowest cooling rates, being it formed by the presence of continuous networks of austenite at the ferritic grain boundaries, as well as of Widmanstatten and intragranular austenite within increasingly coarse ferritic grains (Figures 11 to 13). On the other hand, microstructural analysis has not noticed the occurrence of sigma phase or secondary austenite at the 2205 DSS HAZ. Secondary austenite formation is favored when weldment is submitted to reheating cycles, as that occurring in multipass welding, but since this procedure was not adopted in this present study, secondary austenite formation could has been suppressed.

The proximity with the fusion boundary coupled to the very high peak temperatures makes possible the full dissolution of the austenite during heating and promotes a forceful ferritic grain growth at the HTHAZ ${ }^{2,5,31,34,35}$. Figure 14 shows the relationship between the ferritic grain size and the heating rate that was calculated in a place where the peak temperature has reached $1300{ }^{\circ} \mathrm{C}$ in each one of the investigated welding condition (Table 2 ). As can be seen in

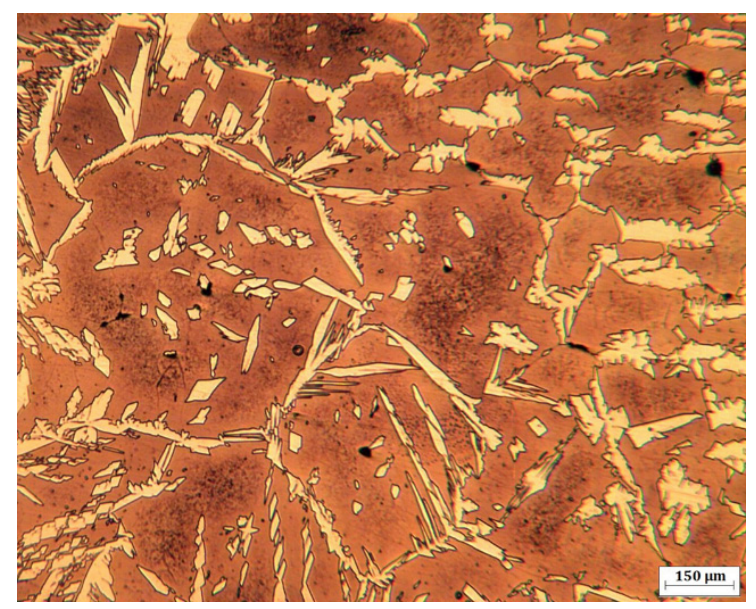

Figure 11. Microstructure from the $2205 \operatorname{DSS} \operatorname{HTHAZ}\left(0.6 \mathrm{~kJ} \mathrm{~mm}^{-1}\right)$.

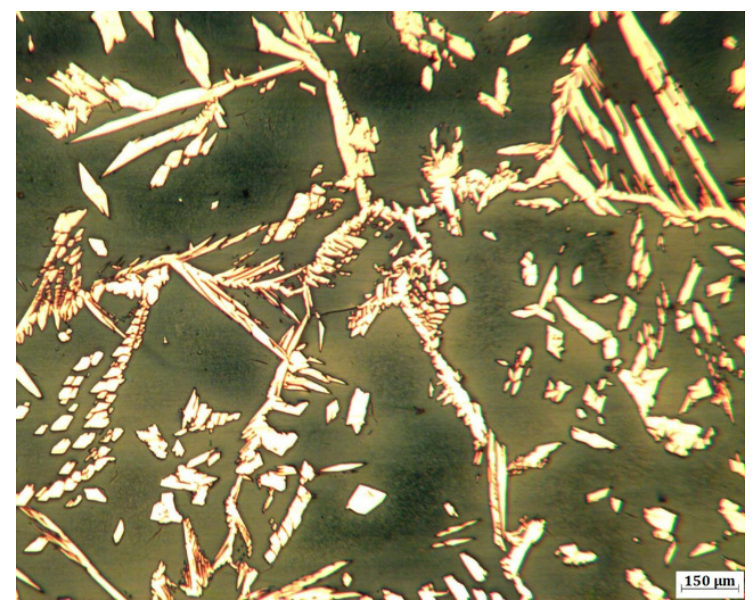

Figure 12. Microstructure from the 2205 DSS HTHAZ $\left(1.6 \mathrm{~kJ} \mathrm{~mm}^{-1}\right)$.
Figure 14, lower heating rates were reached when heat input increased which, in your turn, has contributed to promote the ferritic grain growth after austenite dissolution on heating.

Austenite has reformed during cooling after its dissolution on heating and it can be found in Figure 15 the relationship between the measured austenite content and the corresponding cooling rates locally calculated at the HTHAZ, where peak temperature has also achieved $1300{ }^{\circ} \mathrm{C}$. These calculated cooling rates corresponds to the each one of the investigated welding conditions (Table 2) and a slight reduction at the austenite content was noticed when the cooling rate has decreased. This slight reduction may be attributed to the greater ferritic grain size (Figure 14), which has been enough to compensate an expected increase in the austenite amount due to lowest cooling rates and it suggests that the prior ferrite grain size also plays an essential role on the austenite reformation rate at the DSS HAZ. Nevertheless, the austenite content still lies into the acceptable values for DSS applications ${ }^{2,29}$.

Experimental results showed that sigma phase has not precipitated at the 2205 DSS HAZ using a range of heat input from 0.6 to $2.6 \mathrm{~kJ} \mathrm{~mm}^{-1}$. Indeed, some authors ${ }^{17,36}$ have claimed that very low cooling rates $\left(<0.25{ }^{\circ} \mathrm{C} \mathrm{s}^{-1}\right)$

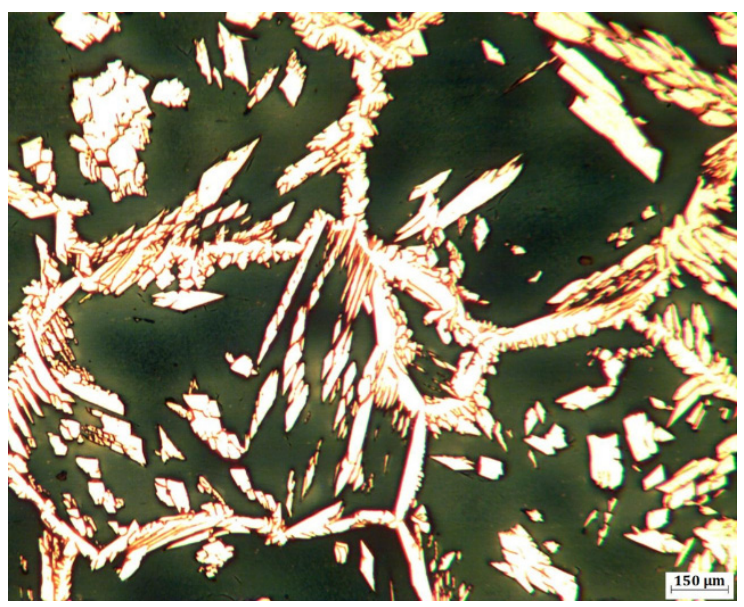

Figure 13. Microstructure from the $2205 \operatorname{DSS} \operatorname{HTHAZ}\left(2.6 \mathrm{~kJ} \mathrm{~mm}^{-1}\right)$.

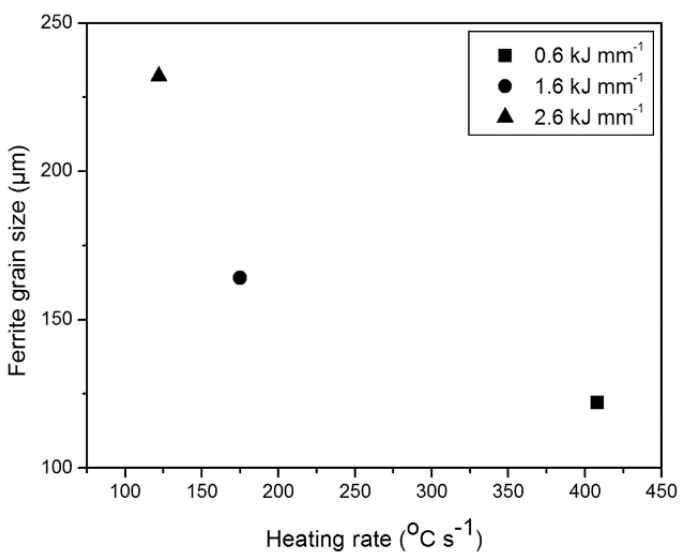

Figure 14. Ferritic grain size versus locally calculated heating rates at the HTHAZ. 
are necessary to form sigma phase in 2205 DSS. Figure 16 shows a comparison among the calculated cooling curves in this work from a peak temperature at the HAZ of about $1200{ }^{\circ} \mathrm{C}$ and some necessary values of the cooling rate for the formation of a certain amount of sigma phase. The cooling rates reached in this study were always higher than the critical to form some sigma phase, which would justify the absence of this intermetallic compound at the 2205 DSS HAZ.

\subsubsection{Fusion zone}

Energy from the welding source causes rapid heating and metal localized fusion. In the FZ the microstructure is significantly affected, impairing the main advantages of the DSS, i.e., the balanced fraction between the austenite and ferrite phases originally present in the parent metal, which may degrade their attractive properties. This unbalance is mainly attributed to the greater difficulty for austenite formation at the FZ due to the elevated cooling rates experimented by this weld region. Figure 17 shows that ferrite is the single phase that forms directly from the liquid for the 2205 DSS, with the subsequent transformation ferrite-austenite only occurring when the alloy is already in solid state.

Figures 18 to 20 show the representative microstructures from the 2205 DSS FZ using heat inputs of $0.6,1.6$ and $2.6 \mathrm{~kJ} \mathrm{~mm}^{-1}$ and the shielding gasses A and B (Table 3). Regardless of the kind of employed shielding gas, massive austenite took place as result of slower cooling rates, i.e., with increasing heat input. Furthermore, when using the nitrogen-containing shielding gas A (Table 3), more austenite was comparatively formed and a meaningful influence on the morphology of this phase was also observed.

The average content of nitrogen present at the $\mathrm{FZ}$ was 0.177 and $0.138 \%$ when using shielding gasses A and B respectively. This finding meaning that shielding gas A was more effective in upholding of higher nitrogen levels in the weld. Despite the apparently negligible difference between the shielding gasses A and B concerning to the nitrogen content present in FZ, it is important to point out that even a slight increase in the content of this major element is already enough to influence the austenite volume fraction in DSS welds ${ }^{38-40}$. Thus, recommendations have been done towards of preventing its loss during DSS welding, aiming to ensure the attractive properties of this material after welding by achieving an adequate balance between the austenite and ferrite phases ${ }^{41}$.

Nitrogen has also remarkable influence on the ferriteaustenite solvus line (Figure 17), which is shifted to higher temperatures, promoting both thermodynamically and kinetically the ferrite-to-austenite transformation, besides still of acting on the own morphology of the resultant austenite $^{38,40}$. In this study, a comparatively greater amount of coarse austenite types grain boundary allotriomorphs and Widmanstatten side-plates were formed at the 2205 DSS FZ when using shielding gas A, which became prevailing mainly with increasing heat input or lower cooling rates (Figures 18a to 20a). Indeed, the combined effects of lower cooling rates due to the increasing heat input and to the shifting of solves line, attributed to the nitrogen, have favored these austenite morphologic types, since they occur in higher temperatures, requiring relatively smaller driving force and lower undercooling ${ }^{1,38}$.

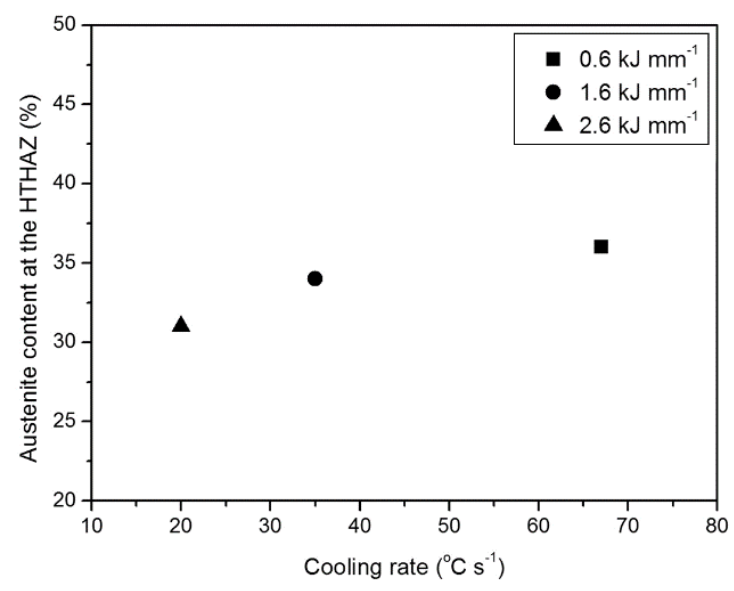

Figure 15. Austenite content versus locally calculated cooling rates at the HTHAZ.

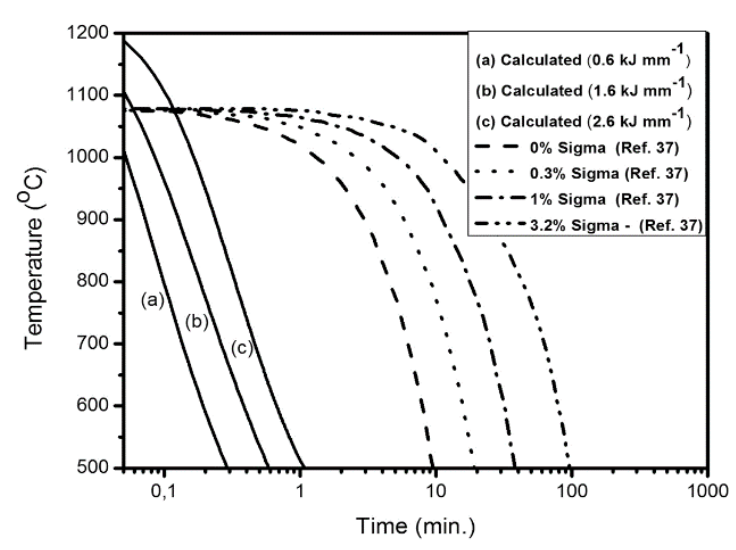

Figure 16. Comparison between calculated cooling curves and selected curves for sigma phase precipitation during continuous cooling of 2205 DSS.

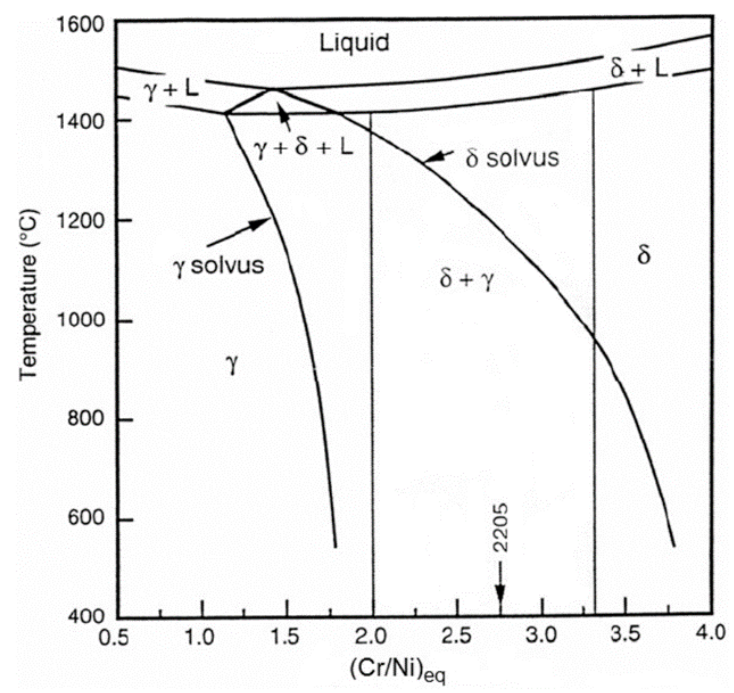

Figure 17. Pseudo-binary diagram based on WRC-1992 equivalent relationships ${ }^{37}$. 


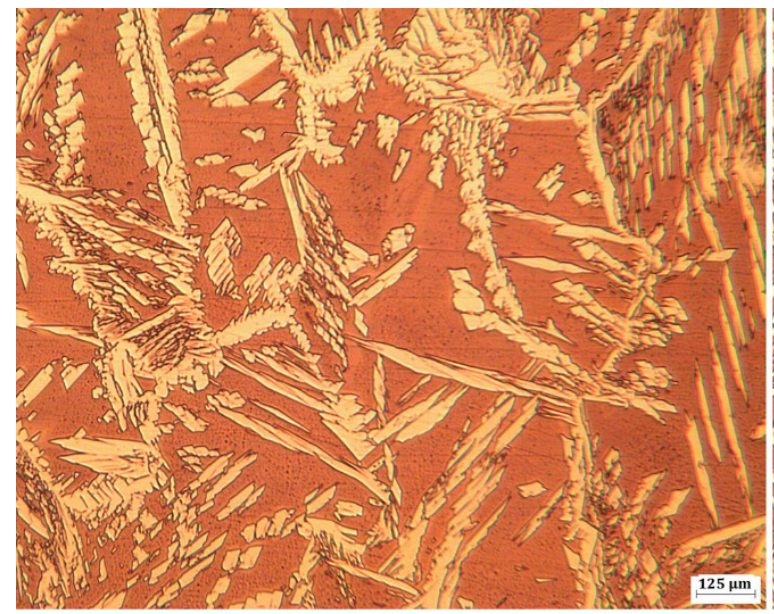

(a)

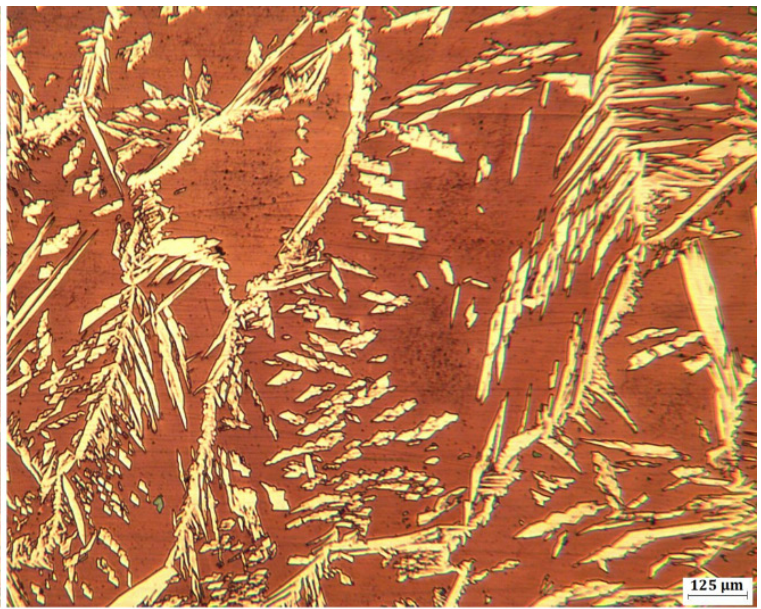

(b)

Figure 18. Microstructure from the 2205 DSS FZ: (a) shielding gas A (b) shielding gas B. $\left(0.6 \mathrm{~kJ} \mathrm{~mm}^{-1}\right)$.

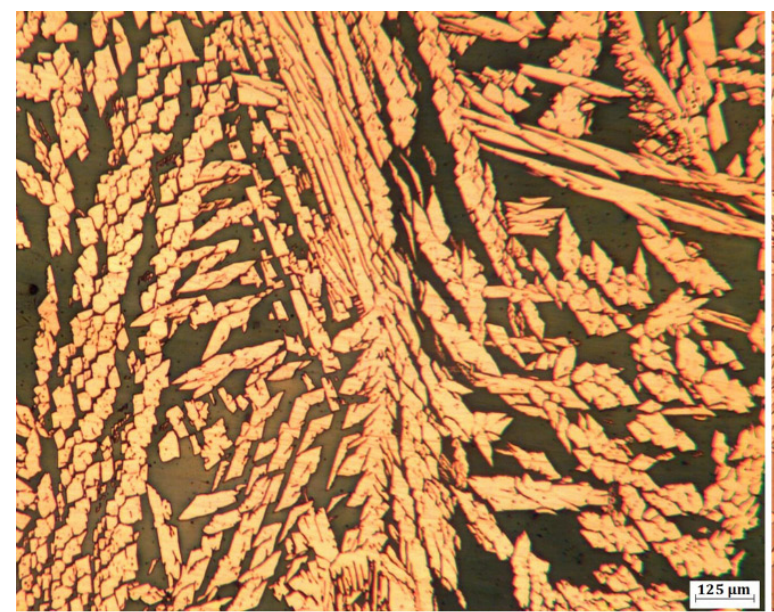

(a)

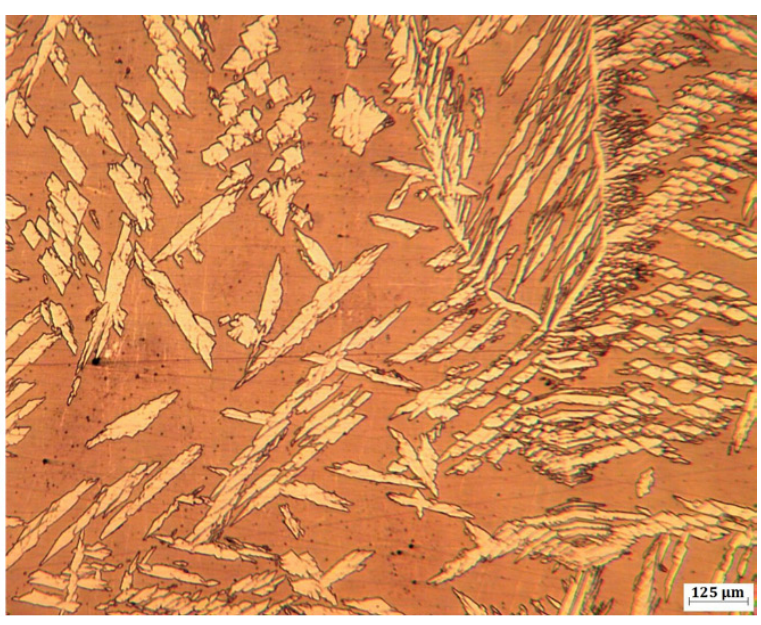

(b)

Figure 19. Microstructure from the 2205 DSS FZ: (a) shielding gas A (b) shielding gas B. $\left(1.6 \mathrm{~kJ} \mathrm{~mm}^{-1}\right.$.

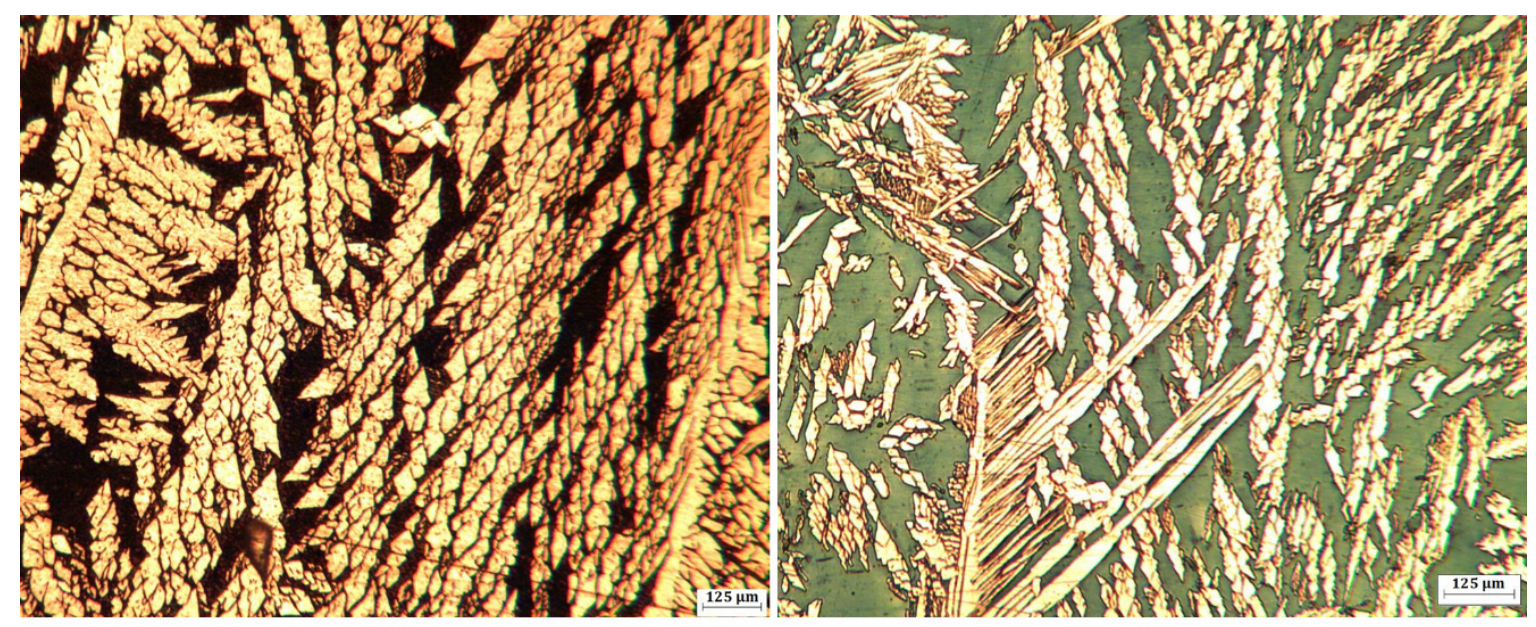

(a)

Figure 20. Microstructure from the 2205 DSS FZ: (a) shielding gas A (b) shielding gas B. $\left(2.6 \mathrm{~kJ} \mathrm{~mm}^{-1}\right)$. 


\section{Conclusion}

A study related to the microstructural changes when DSS are welded was carried out in this work based on experimental observations and numerical simulations. By using the numerical simulation it was possible to predict the thermal history and evaluate the thermal cycles to calculate locally the heating and cooling rates occurring during the welding of a 2205 DSS. Thus, the results are summarised below.

1) Complex thermal cycles and elevated heating and cooling rates are developed during welding, being these phenomena able of entirely modifying the balanced microstructure of the parent metal.

2) The heating rate has revealed to possess a significant effect on the ferritic grain size at the 2205 DSS HTHAZ.

3) The austenite reformation rate at the HTHAZ was directly affected by the prior ferritic grain size. Anyway, the austenite content still has remained into recommended range for 2205 DSS application when using the imposed conditions in this study.

4) Coarse ferritic grains are harmful for DSS toughness besides of impairing the austenite reformation at the HAZ which, in your turn, also adversely affects this important property. Thus, welding parameters must be controlled in order to avoid coarse ferritic grains at the DSS HAZ, which will contribute to reach an enhanced balance between the ferrite and austenite phases and, accordingly, in obtaining of adequate properties for use.

5) No evidence of the sigma phase formation or secondary austenite was noticed at the 2205 DSS HAZ in each one of the evaluated welding conditions. Indeed, the calculated results from the numerical simulation has demonstrated that the cooling rates always remained above from those reported as critical for sigma phase precipitation in 2205 DSS.

6) Besides to be a powerful austenite former at the DSS FZ, nitrogen also presents a meaningful

\section{References}

1. Muthupandi V, Srinivasan PB, Seshadri SK and Sundaresan S. Effect of weld metal chemistry and heat input on the structure and properties of duplex stainless steel welds. Materials Science and Engineering A. 2003; 358(1-2):9-16. http://dx.doi. org/10.1016/S0921-5093(03)00077-7.

2. Jana S. Effect of heat input on the HAZ properties of two duplex stainless steels. Journal of Materials Processing Technology. 1992; 33(3):247-261. http://dx.doi.org/10.1016/0924-0136(92)90211-A.

3. Topolska S and Labanowski J. Effect of microstructure on impact toughness of duplex and superduplex stainless steels. Journal of Achievements in Materials and Manufacturing Engineering. 2009; 36:142-149.

4. Atamert $\mathrm{S}$ and King JE. Sigma-phase formation and its prevention in duplex stainless steels. Journal of Materials Science Letters. 1993; 12(14):1144-1147. http://dx.doi.org/10.1007/BF00420548. influence on the morphology of this phase. Thus, nitrogen could be recommended in opposing to the deleterious effects from the faster cooling rates on the austenite formation, aiming to obtain a beneficial microstructural balance in DSS welds.

7) A suitable microstructure may be obtained in DSS welds by using the GMAW process. An interesting feature of the GMAW process is the possibility of using different kinds of gaseous mixture as shielding gas, which is a further advantage in order to control both the quality and the microstructure of the weld.

8) In this study a proposed numerical model was able to predict, among others, the local heating and cooling rates occurring during the DSS welding, which makes possible to evaluate their effects on the microstructural features in different regions affected by the weld, having proved to be an important tool to be employed in studies not only related to DSS welding, but for other metal alloys also. These features from the numerical model make it possible to obtain in future simulations the mechanical properties values, as well to predict directly both qualitatively and quantitatively the phases formed in a localized way. Hence, the simulation procedure reproduces virtually the path of the thermophysical properties, temperature and properties of local positions throughout the time and may indicate phase and mechanical property changes in the regions affected by the welding in comparison with the parent metal.

\section{Acknowledgements}

The authors are grateful to Aperam South America, ESAB and White Martins (Praxair, Inc.) for supplying the materials and for the valuable information for the development of this work, besides CNPq, FINEP, FAPERJ and CAPES. Thanks are also given to the graduated student B. H. D. Guimarães and to the laboratory technician C. J. Marcelo by the technical support.

5. Chen TH and Yang JR. Microstructural characterization of simulated heat affected zone in a nitrogen-containing 2205 duplex stainless steel. Materials Science and Engineering A. 2002; 338(1-2):166-181. http://dx.doi.org/10.1016/S09215093(02)00065-5.

6. Zhang W, Debroy T, Palmer T and Elmer J. Modeling of ferrite formation in a duplex stainless steel weld considering non-uniform starting microstructure. Acta Materialia. 2005; 53(16):44414453. http://dx.doi.org/10.1016/j.actamat.2005.05.040.

7. Nowacki $J$ and Lukojc A. Microstructural transformations of heat affected zones in duplex steel welded joints. Materials Characterization. 2006; 56(4-5):436-441. http://dx.doi. org/10.1016/j.matchar.2006.02.007.

8. Smith L, Celant M and Pourbaix A. A guideline to the successful use of duplex stainless steels for flow lines. In: Proceedings of Duplex America 2000 Conference; 2000; Houston, Texas. Stainless Steel World; 2000. p. 17-30. 
9. Badji R, Maza H, Belhessa B, Bettahar K, Bouabdallah M, Bacroix B, et al. Microstructure and microhardness of welded and annealed 2205 duplex stainless steel. In: Proceedings of Materiaux Conference; 2006; Dijon, France. Fédération Française des Matériaux; 2006. p. 1-9.

10. Cortie MB and Jackson EMLEM. Simulation of the precipitation of sigma phase in duplex stainless steels. Metallurgical and Materials Transactions. A, Physical Metallurgy and Materials Science. 1997; 28(12):2477-2484. http://dx.doi.org/10.1007/ s11661-997-0005-x.

11. Chen TH, Weng KL and Yang JR. The effect of high-temperature exposure on the microstructural stability and toughness property in a 2205 duplex stainless steel. Materials Science and Engineering A. 2002; 338(1-2):259-270. http://dx.doi. org/10.1016/S0921-5093(02)00093-X.

12. Calliari I, Zanesco M and Ramous E. Influence of isothermal aging on secondary phases precipitation and toughness of a duplex stainless steel SAF 2205. Journal of Materials Science. 2006; 41(22):7643-7649. http://dx.doi.org/10.1007/s10853006-0857-2.

13. He Y-L, Zhu N-Q, Lu X-G and Li L. Experimental and computational study on microstructural evolution in 2205 duplex stainless steel during high temperature aging. Materials Science and Engineering A. 2010; 528(2):721-729. http://dx.doi. org/10.1016/j.msea.2010.09.067.

14. Kuroda T. Role of sigma phase on hydrogen embrittlement of super duplex stainless steels. Transactions of JWRI. 2005; 34:63-68.

15. Maehara Y, Koike M, Fujino N and Kunitake T. Precipitation of fase $\mathrm{s}$ in $25 \mathrm{Cr}-7 \mathrm{Ni}-3 \mathrm{Mo}$ duplex phase stainless steel. Transactions of the ISIJ. 1983; 23:240-246.

16. Calliari I, Zanesco M, Ramous E and Bassani P. Effects of isothermal ageing and continuous cooling after solubilization in a duplex stainless steel. Journal of Materials Engineering and Performance. 2007; 16(1):109-112. http://dx.doi.org/10.1007/ s11665-006-9017-8.

17. Chiu $\mathrm{LH}, \mathrm{Hsieh} \mathrm{WC}$ and $\mathrm{Wu} \mathrm{CH}$. Cooling rate effect on vacuum brazed joint properties for 2205 duplex stainless steels. Materials Science and Engineering A. 2002; A354:82-91.

18. Mahajanam SPV, Case RP, Rincon HE, McIntyre DR, Joosten MW, Gjesdal S, et al. Effect of sigma phase on the corrosion and stress corrosion of 2205 and 2507 duplex stainless steels. In: Proceedings of Corrosion 2011 Conference \& Expo; 2011; Houston, Texas. NACE International; 2011. p. 1-16.

19. Deng B, Wang Z, Jiang Y, Wang H, Gao J and Li J. Evaluation of localized corrosion in duplex stainless steel aged at $850^{\circ} \mathrm{C}$ with critical pitting temperature measurement. Electrochimica Acta. 2009; 54(10):2790-2794. http://dx.doi.org/10.1016/j. electacta.2008.11.038

20. Lara NO, RuizA, Rubio C, Ambriz RR and Medina A. Nondestructive assessing of the aging effects in 2205 duplex stainless steel using thermoelectric power. NDT \& E International. 2011; 44(5):463-468. http://dx.doi.org/10.1016/j.ndteint.2011.04.007.

21. Mathiesen T and Hansen JV. Consequences of sigma phase on pitting corrosion resistance of duplex stainless steel. In: Proceedings of Duplex World 2010 Conference on Force Technology; Beaune, France. KCI Publishing; 2010. p. 1-11.

22. Saeid T, Abdollah-zadeh A, Assadi H and Malek Ghaini F. Effect of friction stir welding speed on the microstructure and mechanical properties of a duplex stainless steel. Materials Science and Engineering A. 2008; 496(1-2):262-268. http:// dx.doi.org/10.1016/j.msea.2008.05.025.

23.van Nassau ML. Le soudage des aciers austenito -ferritiques au Cr-Ni-Mo. Soudage et Techniques Connexes. 1983; 37(1-2):66-70.
24. Ferro P, Tiziani A and Bonollo F. Influence of induction and furnace postweld heat treatment on corrosion properties of SAF 2205 (UNS 31803). Welding Journal. 2008; 87:298s-306s.

25. Nowacki J and Łukojc A. Structure and properties of the heat-affected zone of duplex steels welded joints. Journal of Materials Processing Technology. 2005; 164-165:1074-1081. http://dx.doi.org/10.1016/j.jmatprotec.2005.02.243.

26. Liu $\mathrm{H}, \mathrm{Lu} X$ and Jin $\mathrm{X}$. Phase transformation and mechanical properties in laser continuous heat treatment welds. Materials \& Design. 2011; 32(4):2269-2276. http://dx.doi.org/10.1016/j. matdes.2010.11.016.

27. Garzon CM and Ramirez AJ. Growth kinetics of secondary austenite in the welding microstructure of a UNS S32304 duplex stainless steel. Acta Materialia. 2006; 54(12):3321-3331. http:// dx.doi.org/10.1016/j.actamat.2006.03.018.

28. Zhang Z, Wang Z, Jiang Y, Tan H, Han D, Guo Y, et al. Effect of post-weld heat treatment on microstructure evolution and pitting corrosion behavior of UNS S31803 duplex stainless steel welds. Corrosion Science. 2012; 62:42-50. http://dx.doi. org/10.1016/j.corsci.2012.04.047.

29. Yang Y, Yan B, Li J and Wang J. The effect of large heat input on the microstructure and corrosion behaviour of simulated heat affected zone in 2205 duplex stainless steel. Corrosion Science. 2011; 53(11):3756-3763. http://dx.doi.org/10.1016/j. corsci.2011.07.022.

30. Liou H-Y, Hsieh R-I and Tsai W-T. Microstructure and pitting corrosion in simulated heat-affected zones of duplex stainless steels. Materials Chemistry and Physics. 2002; 74(1):33-42. http://dx.doi.org/10.1016/S0254-0584(01)00409-6.

31. Badji R, Bouabdallah M, Bacroix B, Kahloun C, Belkessa B and Maza $\mathrm{H}$. Phase transformation and mechanical behavior in annealed 2205 duplex stainless steel welds. Materials Characterization. 2008; 59(4):447-453. http://dx.doi.org/10.1016/j. matchar.2007.03.004.

32. Gregori A and Nilsson J-O. Decomposition of ferrite in commercial superduplex stainless steel weld metals; microstructural transformations above $700{ }^{\circ} \mathrm{C}$. Metallurgical and Materials Transactions. A, Physical Metallurgy and Materials Science. 2002; 33(4):1009-1018. http://dx.doi.org/10.1007/s11661-0020202-6.

33. Goldak J, Chakravarti A and Bibby M. A new finite element model for welding heat sources. Metallurgical Transactions. B, Process Metallurgy. 1984; 15(2):299-305. http://dx.doi. org/10.1007/BF02667333.

34. Akselsen, O. M., Fostervoll, H., Ahlen, C. H. Hyperbaric GMA welding of duplex stainless steel at 12 and 35 bar. Welding Journal. 2009; 88(2):21s-28s.

35. Kordatos JD, Fourlaris G and Papadimitriou G. The effect of cooling rate on the mechanical and corrosion properties of SAF 2205 (UNS 31803) duplex stainless steel welds. Scripta Materialia. 2001; 44(3):401-408. http://dx.doi.org/10.1016/ S1359-6462(00)00613-8.

36. Chen TH and Yang JT. Effects of solution treatment and continuous cooling on $\sigma$-phase precipitation in a 2205 duplex stainless steel. Materials Science and Engineering A. 2001; 311(1-2):28-41. http://dx.doi.org/10.1016/S0921-5093(01)00911-X.

37. Kotecki, D. J., Siewert, T. A. Constitution diagram for stainless steel weld metals: a modification of the WRC-1988 diagram. Welding Research Supplement. 1992; 5:171s-177s.

38. Muthupandi V, Srinivasan PB, Shankar V, Seshadri SK and Sundaresan S. Effect of nickel and nitrogen addition on the microstructure and mechanical properties of power beam processed duplex stainless steel (UNS 31803) weld metals. 
Materials Letters. 2005; 59(18):2305-2309. http://dx.doi. org/10.1016/j.matlet.2005.03.010.

39. Atamert $\mathrm{S}$ and King JE. Elemental partitioning and microstructural development in duplex stainless steel weld metal. Acta Metallurgica et Materialia. 1991; 39(3):273-285. http://dx.doi. org/10.1016/0956-7151(91)90306-L.

40. Ogawa, T., Koseki, T. Effect of composition profiles on metallurgy and corrosion behavior of duplex stainless steel weld metals. Welding Journal Research Supplement. 1989; 68(5):181s-191s.

41. Hertzman S, Ferreira PJ and Brolund B. An experimental and theoretical study of heat-affected zone austenite reformation in three duplex stainless steels. Metallurgical and Materials Transactions. A, Physical Metallurgy and Materials Science. 1997; 28(2):277-285. http://dx.doi.org/10.1007/s11661-9970130-6.
42. Patankar SV. Numerical heat transfer and fluid flow. New York: McGraw-Hill; 1984.

43. Patankar SV and Spalding DB. A calculation procedure for heat, mass and momentum transfer in three-dimensional parabolic flows. International Journal of Heat and Mass Transfer. 1972; 15(10):1787-1806. http://dx.doi.org/10.1016/00179310(72)90054-3.

44. Melaaen MC. Calculation of fluid flows with staggered and nonstaggered curvilinear nonorthogonal grids-the theory. Numerical Heat Transfer Part B. 1992; 21(1):1-19. http:// dx.doi.org/10.1080/10407799208944919.

45. Karki KC and Patankar SV. Calculation procedure for viscous incompressible flows in complex geometries. Numerical Heat Transfer. 1988; 14:295-307.

46. Thompson JF, Warsi ZUA and Mastin CW. Numerical grid generation appendix C-3. North Holland, New York; 1985. 


\section{Appendix A. Discretization of the energy equation.}

In order to solve the temperature field coupled with changes of thermophysical properties, the general energy transport equation can be written with the temperature as dependent variable, shown in Equation A1.

$\frac{\partial}{\partial t}\left(\rho C_{p} T\right)+\operatorname{div}\left[\rho C_{p}(\vec{U}) T\right]=\operatorname{div}[k(\operatorname{grad}(T))]+S$

Aiming to obtain the solution of Equation A1 in an arbitrary geometry, the Finite Volume Method (FVM) can be applied in its integral form. Hence, in order to obtain the numerical parameters to represent the discretized form into an irregular mesh some mathematical relations are need. Based on Figure A1, let us define $\left(x^{1}, x^{2}, x^{3}\right)$ : Cartesian system and $\left(\xi^{1}, \xi^{2}, \xi^{3}\right)$ : the general curvilinear non-orthogonal system. Two distinct frames of basis vectors can be defined at any point in a curvilinear non-orthogonal system. The socalled covariant basis vectors, that follows the coordinate lines being tangents at any point and the contravariant basis vectors, which are perpendicular to the surface defined by two of the covariant vectors.

Considering the basis vector shown in Figure A1, the Equations A2 and A4 define the Cartesian components of these base vectors, respectively.

$a_{i}=\frac{\partial x^{k}}{\partial \xi^{i}} I_{k}=J_{i}^{k} I_{k}$

$J_{i}^{k}=\frac{\partial x^{k}}{\partial \xi^{i}}$

$a^{i}=\frac{\partial \xi^{i}}{\partial x^{k}} I_{k}=\bar{J}_{k}^{i} I_{k}$

$\bar{J}_{k}^{i}=\frac{\partial \xi^{i}}{\partial x^{k}}$

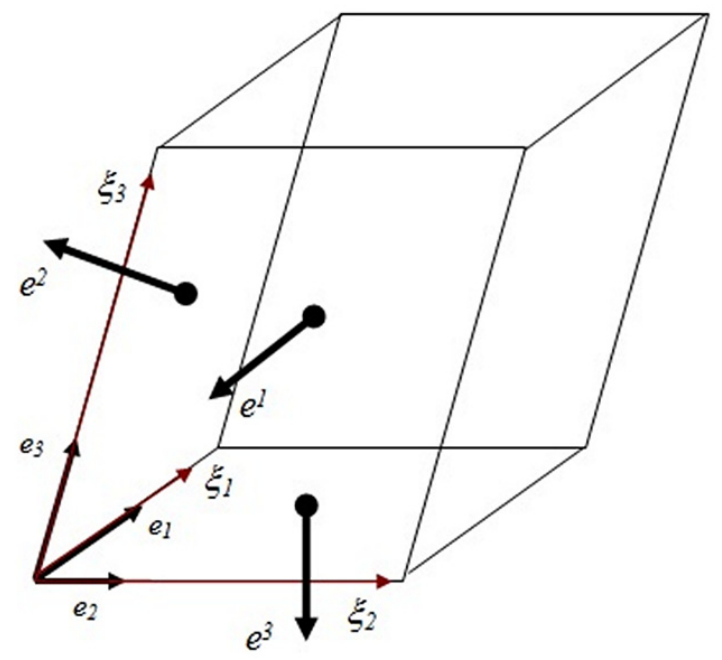

Figure A1. Covariant and contravariant basis vector.
In order to relate the derivatives of the temperature field in these coordinates systems the chain rule is used as follows:

$$
\begin{gathered}
\frac{\partial T}{\partial \xi^{i}}=\frac{\partial x^{j}}{\partial \xi^{i}} \frac{\partial T}{\partial x^{j}}=J_{i}^{j} \frac{\partial T}{\partial x^{j}} \\
\frac{\partial T}{\partial x^{i}}=\frac{\partial \xi^{j}}{\partial x^{i}} \frac{\partial T}{\partial \xi^{j}}=\bar{J}_{i}^{j} \frac{\partial T}{\partial \xi^{j}}
\end{gathered}
$$

The determinant of the Jacobian related to the coordinates transformation is defined by Equation A8, with the rows and columns of the matrix formed by the derivatives of the coordinates transformation. These quantities give the necessary information of the coordinate transformation needed to express the discretized form of the energy transport equation.

$$
J=\operatorname{det}\left|\begin{array}{lll}
\frac{\partial x^{l}}{\partial \xi^{l}} & \frac{\partial x^{l}}{\partial \xi^{2}} & \frac{\partial x^{l}}{\partial \xi^{3}} \\
\frac{\partial x^{2}}{\partial \xi^{1}} & \frac{\partial x^{2}}{\partial \xi^{2}} & \frac{\partial x^{2}}{\partial \xi^{3}} \\
\frac{\partial x^{3}}{\partial \xi^{l}} & \frac{\partial x^{3}}{\partial \xi^{2}} & \frac{\partial x^{3}}{\partial \xi^{3}}
\end{array}\right|
$$

The Cartesian components of the contravariant basis vector are evaluated by the following expression:

$a^{i}=\frac{1}{J}\left(a_{j} x a_{k}\right)(\mathrm{i}, \mathrm{j}, \mathrm{k}$ cyclic $)$

Thus, the Jacobian of the coordinate transformation being evaluated, all necessary information can be evaluated at any point of the physical domain. The components of the Jacobian matrix can be numerically determined (computational space approach) or by the direct calculation of the area vectors and volume in the physical space (physical space approach). We have chosen the computational space approach, which is suitable for numerical implementations. The covariant and contravariant metric tensors components can be written from the basis vectors components. Thus, the nine components are:

$$
\begin{aligned}
& g_{i j}=a_{i} \cdot a_{j}=J_{i}^{k} J_{j}^{k} \\
& g^{i j}=a^{i} \cdot a^{j}=\bar{J}_{k}^{i} \bar{J}_{k}^{j}
\end{aligned}
$$

The area vectors generated by two of the covariant vectors are given by:

$$
A^{(i)}=a_{j} \times a_{k}(\mathrm{i}, \mathrm{j}, \mathrm{k} \text { cyclic })
$$

The geometric diffusion coefficient is defined by:

$G^{i j}=\frac{A_{k}^{i} A_{k}^{j}}{J}$

By using Equations A1 to A13 all the necessary information of the coordinate transformation is given. These equations relate the physical space with the computational space and this is currently used to obtain the discretized form of the energy conservation equation (Equation A1). In the next section, the discretized form of a general state variable is deduced. 


\section{Discretization of the general energy conservative equation}

The discretization of the general energy conservation equation is based on the finite volume method ${ }^{42}$. The coordinate invariant Equation A14 is integrated over a general control volume in the physical space and then, the Gauss divergence theorem is applied to transform the volume integral into a surface integral.

$$
\int_{\delta t} \int_{\delta V} \frac{\partial\left(\rho C_{p} T\right)}{\partial t} d v d t+\int_{\delta t} \int_{\delta V} d i v\left(\rho \vec{U} C_{p} T-k \operatorname{grad} T\right) d v d t=\int_{\delta t} \int_{\delta V} S d v d t(\mathrm{~A}
$$

Figure A2 illustrates the concept of the finite volume method, where the average value of the dependent variable is assumed to prevail over all the control volume centered in the point $\mathrm{P}$. Notation presented in Figure A2 is as follows: w-west face, e-east face, s-south, n-north, b-bottom and t-top. For the computational molecule similar notation applies W-West, E-east, S-south, N-north, B-bottom and T-top volumes. Hence, from now this notation will be used to identify the faces of the control volumes while the capital letters will identify the neighborhood points. In order to simplify the integral form of the energy conservation equation (Equation A14), let us define a flux tensor, $\mathrm{F}$, as follows:

$F=\stackrel{I}{U} C_{p} T-k \nabla T$

Hence, the control volume integration from the Equation A14, without the transient term, is given by using Equation A15 and the Gauss theorem. The transient terms will be detailed later.

$$
\begin{aligned}
& F .\left.A\right|_{e}-\left.F \cdot A\right|_{w}+\left.F \cdot A\right|_{n}-\left.F \cdot A\right|_{s}+\left.F \cdot A\right|_{t}-\left.F \cdot A\right|_{b}=S_{c}+S_{P} T_{P} \\
& F .\left.A\right|_{e}=\int_{A_{e}} F \cdot d A=\left.\left(\rho U \cdot A^{(I)} C_{p} T-k A^{(I)} \cdot \nabla T\right)\right|_{A_{e}}=\left.F^{I}\right|_{e} \\
& \left.F \cdot A\right|_{n}=\int_{A_{n}} F \cdot d A=\left.\left(\rho U \cdot A^{(2)} C_{p} T-k A^{(2)} \cdot \nabla T\right)\right|_{A_{n}}=\left.F^{2}\right|_{n}
\end{aligned}
$$

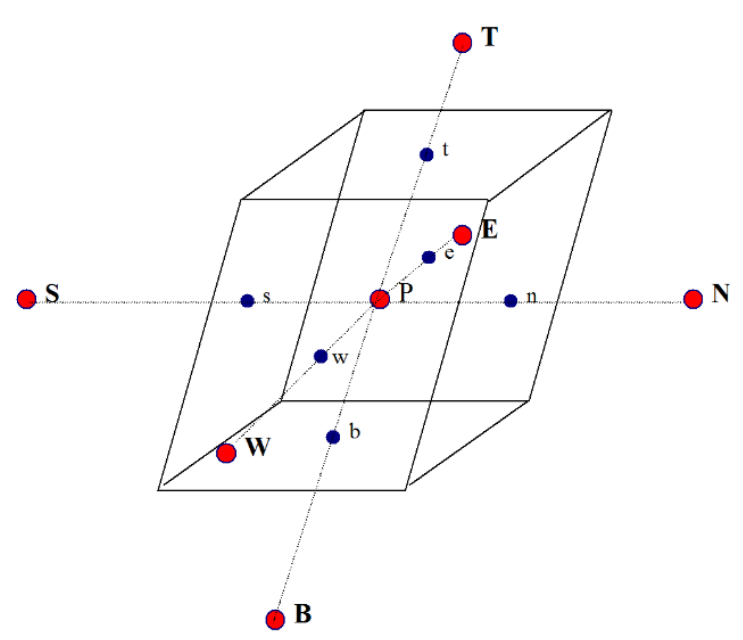

Figure A2. Schematic molecule of a 3-D control volume.

$$
F .\left.A\right|_{t}=\int_{A_{t}} F \cdot d A=\left.\left(\rho U \cdot A^{(3)} C_{p} T-k A^{(3)} . \nabla T\right)\right|_{A_{t}}=\left.F^{3}\right|_{t}
$$

$$
\left.F^{1}\right|_{e}=\left(\rho U^{1} C_{p} T-k\left(G^{11} \frac{\partial T}{\partial \xi^{1}}+G^{12} \frac{\partial T}{\partial \xi^{2}}+G^{13} \frac{\partial T}{\partial \xi^{3}}\right)\right)_{A_{e}}
$$

$$
\left.F^{2}\right|_{n}=\left(\rho U^{2} C_{p} T-k\left(G^{21} \frac{\partial T}{\partial \xi^{1}}+G^{22} \frac{\partial T}{\partial \xi^{2}}+G^{23} \frac{\partial T}{\partial \xi^{3}}\right)\right)_{A_{n}}
$$

$$
\left.F^{3}\right|_{t}=\left(\rho U^{3} C_{p} T-k\left(G^{31} \frac{\partial T}{\partial \xi^{1}}+G^{32} \frac{\partial T}{\partial \xi^{2}}+G^{33} \frac{\partial T}{\partial \xi^{3}}\right)\right)_{A_{t}}
$$

Similar expressions are given for $\mathrm{w}, \mathrm{s}$ and $\mathrm{b}$ faces. $\mathrm{U}^{1}$, $\mathrm{U}^{2}$ and $\mathrm{U}^{3}$ are the normal velocities to the faces e, $\mathrm{n}$ and $\mathrm{t}$, respectively.

Transient term is included before the presentation of the final form of the discretized conservation equation. In this point, we have to take a decision on which method the time discretization will be derivative. Several methods have been proposed in the literature ${ }^{42-46}$. However, for non-linear problems, the fully implicit method is selected due to its stability and the guarantee of always meaningful solution even for strong non-linearly problems. Therefore, it is a suitable method to be applied for the welding process simulation. In this scheme the "new" value of the dependent variable is assumed to be same throughout the time step. The transient term is then discretized as:

$\int_{\delta v} \frac{\partial\left(\rho C_{p} T\right)}{\partial t} d v \approx \frac{\left(J_{p} \rho C_{P} T-J_{p}^{0} \rho_{p}^{0} C_{p}^{0} T_{P}^{0}\right)}{\Delta t}$

If the above equations are substituted in Equation A14, the general discretized equation becomes:

$$
a_{P} T_{P}=a_{W} T_{W}+a_{E} T_{E}+a_{B} T_{B}+a_{T} T_{T}+a_{S} T_{S}+a_{N} T_{N}+b
$$

where

$$
a_{P}=a_{W}+a_{E}+a_{B}+a_{T}+a_{S}+a_{N}+J_{p} \frac{\rho C_{p}}{\Delta t}-S_{P}
$$

and

$$
\begin{aligned}
b= & b_{N O}+S_{C}+J_{p}^{0} \frac{\rho^{0} C_{p}^{0}}{\Delta t} T_{p}^{0} \\
b_{N O} & =\left[\Gamma G^{I 2} \frac{\partial T}{\partial \xi^{2}}+\Gamma G^{13} \frac{\partial T}{\partial \xi^{3}}\right]_{w}^{e}+\left[\Gamma G^{21} \frac{\partial T}{\partial \xi^{1}}+\Gamma G^{23} \frac{\partial T}{\partial \xi^{3}}\right]_{s}^{n} \\
& +\left[\Gamma G^{31} \frac{\partial T}{\partial \xi^{1}}+\Gamma G^{32} \frac{\partial T}{\partial \xi^{2}}\right]_{b}^{t}
\end{aligned}
$$

The coefficients in Equation A24 are determined by the power law scheme ${ }^{42-45}$, as shown in Table A1. 
Table A1. Power law coefficients for the discretized general conservative equation.

$$
\begin{array}{cc}
a_{E}=D_{e} A\left(P_{e}\right) ; P_{e}=\frac{C_{e}^{l}}{D_{e}} ; D_{e}=\left.k G^{11}\right|_{e} & a_{W}=D_{w} A\left(-P_{w}\right) ; P_{w}=\frac{C_{w}^{l}}{D_{w}} ; D_{w}=\left.k G^{11}\right|_{w} \\
\begin{array}{c}
A\left(P_{e}\right)=\min \left\langle 0,\left(1-0.1\left|P_{e}\right|\right)^{5}\right\rangle \\
+\min \left\langle 0,-P_{e}\right\rangle
\end{array} & A\left(-P_{w}\right)=\min \left\langle 0,\left(1-0.1\left|-P_{w}\right|\right)^{5}\right\rangle \\
& +\min \left\langle 0,+P_{w}\right\rangle
\end{array}
$$

\section{Nomenclature}

$\begin{array}{llr}A^{(i)}: & \text { Area vectors generated by two covariant vectors } & {\left[\mathrm{m}^{2}\right]} \\ A_{k}^{i}: & \text { Cartesian components of the area vectors } & {\left[\mathrm{m}^{2}\right]} \\ a^{i}: & \text { Contravariant basis vector } & {[\mathrm{m}]} \\ a_{i}: & \text { Covariant basis vector } & {[\mathrm{m}]} \\ a_{k}: & \text { Coefficients in discretized equation }(\mathrm{k}=\mathrm{W}, \mathrm{E}, \mathrm{S}, \mathrm{N}, \mathrm{B}, \mathrm{T}, \mathrm{P}) & \\ b: & \text { Independent part of the linearized source term } & {\left[\mathrm{kg} \mathrm{s}^{-1}\right]} \\ b_{N O}: & \text { Non-orthogonal part of the linearized source term } & \\ C^{i}: & \text { Convective normal flux } & \\ F: & \text { Flux tensor } & {\left[\mathrm{m}^{-2}\right]} \\ G^{i j}: & \text { Cartesian components of geometric diffusion coefficient } \\ g^{i j}: & \text { Cartesian components of contravariant metric tensor } & {\left[\mathrm{m}^{2}\right]} \\ g_{i j}: & \text { Cartesian components of covariant metric tensor } & {[-]} \\ I_{k}: & \text { Cartesian unit vectors } & {\left[\mathrm{m}^{3}\right]} \\ J: & \text { Jacobian determinant of coordinate transformation (volume in physical space) } & \\ P e: & \text { Peclet number } & {[\mathrm{s}]} \\ S_{\varphi}: & \text { Source term } & {\left[\mathrm{m} \mathrm{s}^{-1}\right]} \\ t: & \text { Time } & {\left[\mathrm{m}^{2}\right]} \\ U_{i}: & \text { Velocity vector of moving grid } & \end{array}$

\section{Greek symbols:}

$\begin{array}{ll}\xi^{i}: & \text { Covariant coordinate system } \\ \rho: & \text { Density }\end{array}$

